\title{
Jenseits des mos maiorum: Eine Archäologie römischer Werte?
}

\author{
BARBARA E. BORG (EXETER)
}

Römische Werte als Gegenstand altertumswissenschaftlicher Forschung? Anders als in der Alten Geschichte und der Latinistik kann man diese Frage für die Klassische Archäologie wohl - paradoxerweise - erst für die Zeit seit den späten $60 \mathrm{er}$ Jahren des letzten Jahrhunderts wirklich mit ,ja' beantworten. Seitdem scheint es allerdings, als habe die römische Archäologie, nach einem sehr mühsamen Start, den römischen Werten, besser vielleicht ,Leitvorstellungen", ihren endgültigen Durchbruch als der griechischen Archäologie ebenbürtige Sparte der Klassischen Archäologie zu verdanken. ${ }^{1}$

\section{Die Entdeckung der römischen Kunst um 1900}

Die Abstinenz gegenüber der römischen Kunst hing in erster Linie mit ihrer Ablehnung als Kunst (oder eben Nicht-Kunst) zusammen. Seit dem späten 18. Jh. ${ }^{2}$ hatte sich ein Kunstbegriff etabliert, welcher von wahrer Kunst Ori-

${ }^{1}$ Der vorliegende Beitrag wurde in verschiedenen Versionen in Dresden, Heidelberg und Berlin vorgetragen und diskutiert. Mein Dank gilt den Einladenden und allen, die bei diesen Gelegenheiten Anregungen und Kritik beigetragen haben, insbesondere Stefan Rebenich und Tonio Hölscher. - Ich bin mir bewußt, daß die hier vorgetragenen Überlegungen nicht eine Forschungsgeschichte zur Römischen Archäologie ersetzen können, sondern in ihrem Anspruch begrenzt sind. Zum einen wurde die Forschungsgeschichte ausdrücklich aus der Perspektive der von den Veranstaltern des Bandes vorgegebenen Fragestellung, also der (möglichen) Rolle der römischen ,Werte' in der archäologischen Wissenschaft dargestellt, und zum zweiten ist fast ausschließlich die deutsche bzw. deutschsprachige Forschung berücksichtigt worden. Die zweite Einschränkung scheint problematischer zu sein als die erste, doch schien mir eine Ausweitung auf die Forschung anderer Länder nicht zuletzt aufgrund des begrenzten Umfangs des Beitrags von vornherein nicht in angemessener Weise möglich zu sein. Insofern wurde auf solche Arbeiten nur dort verwiesen, wo sie einen größeren Einfluß auf die deutschsprachige Forschung besessen haben, die zudem noch weit in die zweite Hälfte des 20. Jhs. hinein auf dem Gebiet der römischen Archäologie relativ autonom agierte.

${ }^{2}$ Auf die Tatsache, daß diese Sicht sich in der Betrachtung der antiken Kunst erst mit Winckelmann durchgesetzt hat, ist mehrfach hingewiesen worden, siehe z. B. O. BRENDEL, Was ist römische Kunst?, Köln 1990 (amer. Original New Haven/London 1979; erstmals in kürzerer Fassung: Prolegomena to a Book on Roman Art, Memoirs of the American Academy in Rome 1953, 9-73); A. H. BoRBEIN, Gerhard Rodenwaldts Bild der römischen Kunst, in: E. GABBA, K. CHRIST (Hgg.), Römische Geschichte und Zeitgeschichte in der deutschen und italienischen Altertumswissenschaft während des 19. und 
ginalität und Autonomie, allgemeine Gültigkeit und idealische Schönheit verlangte. Nicht zuletzt in der Folge antiker Äußerungen, welche die Kunst der Griechischen Klassik als nie wieder erreichten Höhepunkt priesen, vor allem aber gestützt auf das organizistische Entwicklungsmodell des ,Gründerheros' der Klassischen Archäologie, Johann Joachim Winckelmann, von Aufstieg, Blüte, Niedergang und Verfall, behauptete man, allein die griechische Kunst der klassischen Zeit entspreche diesen Forderungen, und zwar sowohl wegen ihrer dem ästhetischen Empfinden der Zeit entgegenkommenden Formen als auch wegen ihrer Themen, der Darstellung von Göttern und Heroen sowie heroenhaften schönen Menschen und deren Taten, welche allgemeingültige Ideale verkörperten.

Dagegen sah man die Bildwerke der Römer als Ausdruck eines phantasielosen Epigonentums und einer allgemeinen kulturellen Dekadenz, mit der man sich bestenfalls zu dem Zweck beschäftigte, verlorene griechische Originale zu rekonstruieren. ${ }^{3}$ Die mehr oder weniger guten römischen Kopien selbst und die den modernen Geschmack noch weniger treffenden Varianten und Pasticcios nach griechischen Vorbildern ließen alles Genialische vermissen, während weniger unmittelbar an griechischen Vorbildern orientierte Werke wie Porträts und Staatsreliefs gleich in zweifacher Hinsicht defizient erschienen: Zum einen entsprachen sie nicht dem Kunst- und Schönheitsideal. Porträts zeigten die Dargestellten oft mit allen physischen Mängeln, während die Staatsreliefs mit ihren Personifikationen als, frostige Allegorien ${ }^{6}$ abgetan wurden. ${ }^{4}$ Zum zweiten schien diese Kunst aber auch ganz auf die Wiedergabe unmittelbarer Lebensrealität gerichtet zu sein, auf Biographisch-Beliebiges oder Punktuell-Historisches, und damit der Forderung an die wahre Kunst nach Allgemeingültigkeit zuwider zu laufen. ${ }^{5}$ So

20. Jahrhunderts, II: L'impero romano fra storia generale e storia locale, Como 1991, 175-200, bes. 176f. mit Nachweisen.

${ }^{3}$ So teilweise noch im 20. Jh., bes. E. BUSCHOR, Technisches Sehen, München 1952; dazu P. ZANKER, Nachahmen als kulturelles Schicksal, in: Probleme der Kopie von der Antike bis zum 19. Jahrhundert. Vier Vorträge, München 1992, 9-24.

${ }^{4}$ Zur Ablehnung des Porträtgenres siehe J. BAŽANT, Roman Portraiture: A History of its History, Prag 1995, 23-28; zur Allegorie in der Kunst siehe B. E. BORG, Der Logos des Mythos, München 2002, bes. 223-235, und DIES., Blinde Flecken: Die frühe griechische Allegorie als Beispiel kollektiver Verdrängung, in: S. ALTEKAMP, M. HOFTER, M. KRUMME (Hgg.), Posthumanistische Klassische Archäologie, Kolloquium Berlin, 19.2.-21.2. 1999, München 2001, 391-400.

${ }^{5}$ Diese Auffassung war so verbreitet, daß sich Nachweise erübrigen; siehe stellvertretend BRENDEL (wie Anm. 2), 36-42; BAŽANT (wie Anm. 4), 23-28 und 43f. Bemerkenswert ist, daß diese modernen Wertungen auch später noch von solchen Archäologen mehr oder weniger offen vertreten werden, die selbst über Römisches arbeiten; siehe z. B. 
setzten Arbeiten zur römischen Kunst im Wesentlichen antiquarische Studien fort oder beschränkten sich auf Materialerschließungen. ${ }^{6}$

Ihren allmählichen Aufstieg verdankt die römische Archäologie vor allem der Abkehr von eben diesen letztlich normativen und universalistischen Parametern. Mit der Etablierung moderner Kunstrichtungen, besonders des Impressionismus, war eine ästhetische Neuorientierung und Abkehr von den vorherrschenden ästhetisch-normativen Vorstellungen möglich geworden, welche neben einer Neubewertung der zuvor ebenfalls verachteten Kunst zeitgenössischer ,primitiver ${ }^{6}$ Völker oder der griechischen archaischen $\mathrm{Kunst}^{7}$ auch eine positivere Aufnahme der römischen Kunst förderte. In Bezug auf letztere legten.hierfür Alois Riegl und Franz Wickhoff den Grundstock. ${ }^{8}$ Beide betonten, man müsse die römische Kunst nicht an modernen (oder angeblich zeitlosen) Maßstäben messen, sondern aus ihrer eigenen Zeit und Kultur heraus bewerten. Aus der Perspektive ihres Interesses an der byzantinischen Kunst und am Mittelalter setzten sie der Dekadenzthese entgegen, es habe sich bei der römischen Kunst vielmehr um eine Weiterentwicklung der antiken Kunst in Richtung auf die christliche Kunst des Mittelalters gehandelt. Wickhoff betonte, hierin dem allgemeinen Interesse seiner Zeit an ,nationalen' Kunstentwicklungen folgend, vor allem die Herkunft unterschiedlicher Stilelemente aus der Kunst

L. M. LANCKOROŃSKI, Das römische Bildnis in Meisterwerken der Münzkunst, Amsterdam u. a. 1944, 9: „Allegorien, Abbreviaturen historischer Ereignisse, wie sie die Rückseitendarstellungen [der Münzen] bringen, bleiben - mit wenigen Ausnahmen geschichtliche Dokumente, ohne ins Kunstwerk gesteigert zu werden" sowie E. BUSCHOR, Das Porträt. Bildniswege und Bildnisstufen in fünf Jahrtausenden, München 1960, 132: „Die Grundlage und der Grundzug des Spiegelporträts [gemeint ist das angeblich ,spiegelbildartige' römische Porträt; B.E.B.] ist, von den älteren Stufen her gesehen, eine zurückgesunkene Form, ein gespenstisches Leichendasein."

${ }^{6}$ Damit soll der Wert dieser Arbeiten als unverzichtbare Grundlage späterer Forschungen keineswegs geschmälert werden; z.B. wurde 1869 von O.JAHN das Sarkophagcorpus begründet; zwischen 1882 und 1894 publizierte J. J. BERNOULLI ein Repertorium römischer Porträts, in dem er eine möglichst vollständige Darstellung aller Schriftquellen und erhaltenen Bildnisse berühmter Personen der Antike anstrebte (J. J. BERNOULlI, Römische Ikonographie, 4 Bde., Stuttgart); 1896-1900 legte C. CICHORIUS in drei Bänden die Reliefs der Trajanssäule in ausgezeichneten Abbildungen vor (C. CICHORIUS, Die Reliefs der Traianssäule, Berlin).

${ }^{7}$ K. SCHEFOLD, Wirkungen Stefan Georges, Castrum Peregrini 173/4, 1986, 72-97, bes. 72-74; G. W. MOST, Zur Archäologie der Archaik, A\&A 35, 1989, 1-23; S. MARChAND, Down from Olympus, Princeton, NJ 1996, 332f.

${ }^{8}$ Zur Bedeutung Riegls und Wickhoffs für die Römische Archöologie siehe u. a. BRENDEL (wie Anm. 2), 43-52; R. BIANCHI BANDINELlI, Klassische Archäologie, München 1978 (italienisches Original Rom 1976), 128-139. 
verschiedener Volksgruppen (Griechen, Etrusker, Italiker) und sah das charakteristisch Römische in der spezifischen Verbindung dieser Elemente. "Ihm stellte sich die römische Kunst als ein nationales Phänomen dar." Riegl hingegen interpretierte die stilistischen Unterschiede vor allem chronologisch als Ausdruck eines zeitbedingten, kollektiven ,Kunstwollens.$^{10} \mathrm{Daß}$ beider Appell zugunsten der römischen Kunst Wirkung zeigte, hängt wohl nicht zuletzt damit zusammen, daß die Klassische Archäologie sich zur selben Zeit insgesamt durch eine Abkehr von Historismus und Positivismus und eine Hinwendung zur Kunstgeschichte im Sinne einer Analyse formaler Gestaltungsprinzipien innerhalb der Altertumswissenschaften - und vor allem von der Philologie - zu emanzipieren suchte. ${ }^{11}$

Die durch Riegl und Wickhoff angestoßene Diskussion kreiste zunächst lange um die heftig umstrittene Frage, was denn eigentlich das Römische an der römischen Kunst sei. Diese Frage wurde nicht nur durch den erstmals als solchen wirklich wahrgenommenen Forschungsgegenstand nahe gelegt - in diesem Falle hätte man sich vermutlich schnell auf eine pragmatische Lösung einigen können -, sondern sie entsprach vor allem auch den Interessen der Zeit an ,nationalen' Kunstformen und ihren Unterschieden. Während die einen das Römische in bestimmten ,ungriechischen“ Stilformen - ,Vernachlässigung des Körperlichen“ und ,mangelndes Empfinden für organische Zusammenhänge ${ }^{6}$, Frontalität, Zentralkomposition, Bedeutungsgröße usw. -, aber auch in der Lebensnähe der Darstellungen fanden, an der man besonders das Verhältnis zum Raum (,Entdeckung der Perspektive ' und Illusionismus, kontinuierende Darstellung) lobte, sahen andere die römische Kunst in formaler Hinsicht lediglich als eine Fort-

${ }^{9}$ BRENDEL (wie Anm. 2), 52; vgl. F. WICKHOFF, in: W. RITTER vON HARTEL, F. WICKHOFF, Die Wiener Genesis, Wien 1895, 1-96; Enciclopedia dell'Arte 7, Roma 1966, 1218f. s.v. Wickhoff, Franz (R. BIANCHI BANDINELLI); I. KALAVREZOUMAXEINER, Franz Wickhoff: Kunstgeschichte als Wissenschaft, in: S. KRENN, M. PIPPAL (Hgg.), Wien und die Entwicklung der kunsthistorischen Methode. Akten des XXV. Internationalen Kongresses für Kunstgeschichte, Wien 4.-10. Sept. 1983, Wien u. a. 1984, 17-27; BAŽANT (wie Anm. 4), 50-55.

${ }^{10}$ A. RIEGL, Stilfragen, Berlin 1893; DERS., Die spätrömische Kunstindustrie nach den Funden in Österreich-Ungarn, I, Wien 1901; dazu Enciclopedia dell'Arte 6, Roma 1965, 683ff. s. v. Riegl, Alois (R. BIANCHI BANDINELLI); BAŽANT (wie Anm. 4), 55-62 mit weiterer Lit. in Anm. 200; C. WATZKA, Form - Inhalt / Kunst - Gesellschaft. Gestaltung und Verhältnis zweier Begriffspaare in Alois Riegls Kunsttheorie, http://wwwgewi.kfunigraz.ac.at/moderne/heft12wa.htm\#wal.

${ }^{11}$ BIANCHI BANDINELLI (wie Anm. 8), 12 und 18-19. Schon die Neubewertung Wickhoffs und Riegls beruhte auf der Lehre des Impressionismus, daß die äußere Form der Inhalt der Kunst sei: BAŽANT (wie Anm. 4), 47-62; vgl. die Bemerkungen von Kekulé von Stradonitz (unten Anm. 15). 
setzung der griechischen Kunst an, welche allerdings inhaltlich - und somit auch ikonographisch - durch das römische ,Ethos' geprägt war, insbesondere durch ein Interesse am historisch Einmaligen, Augenblicklichen und Zufälligen. ${ }^{12}$ Diese Abkehr von Normativität und Positivismus bedeutete letztlich eine Historisierung der Klassischen Archäologie, die jedoch in zwei unterschiedliche, wenn auch gelegentlich miteinander verbundene Richtungen strebte.

\section{Klassische Archäologie als Kunstgeschichte}

Die eine, die Hauptrichtung, sah das Historische an der römischen Kunst ausschließlich in den Veränderungen formaler Elemente und war entsprechend ganz kunsthistorisch im engeren Sinne ausgerichtet. Entsprechende Studien untersuchten vor allem das Verhältnis zur griechischen, etruskischen und italischen Kunst einerseits und zur spätantik-mittelalterlichen Kunst andererseits, wobei die innerhalb der römischen Kunst zu beobachtenden unterschiedlichen Stilelemente wahlweise chronologisch (in der Nachfolge Riegls), meist jedoch ethnologisch oder ,national' (in der Nachfolge Wickhoffs) ${ }^{13}$ oder später dann gelegentlich soziologisch ausgedeutet wurden. ${ }^{14}$ Sie nahmen an dem zeitgenössischen Wertediskurs nur insofern

${ }^{12}$ BRENDEL (wie Anm. 2), 60-126. Vgl. G RODENWALDT, Säulensarkophage, MDAI(R) 38/39, 1923/24, 1-40, hier 1: „Aber eben das, was gefiuhlt und gewollt ist, und nicht, wie es gestaltet ist, ist das Wesentliche in der Kunst der späten Antike. Das gilt nicht erst für die christliche Kunst, sondern schon für die spät-heidnische Antike und vor allem für die römische Kunst. Wer nur die Form betrachtet, wird der römischen Kunst, wie auch der römischen Literatur, nie gerecht werden können; es gilt vielmehr, unter der griechischen Hülle das Ethos des Römertums als den wesentlichen Bestandteil jedes wirklich römischen-Kunstwerks zu erkennen." Siehe außerdem DERS., Eine spätantike Kunstströmung in Rom, MDAI(R) 36/37, 1921/22, 58-110, bes. 59 sowie A. HEKLER, Die Bildniskunst der Griechen und Römer, Stuttgart 1912.

${ }^{13}$ Das ,ethnologische" oder rassekundliche Interesse der Forschung scharf erkannt von R. BIANCHI BANDINELLI, Römische Kunst, zwei Generationen nach Wickhoff, Klio 38, 1960, 267-283, hier 269: ,Man muß gestehen, daß stattdessen - wenn auch nicht immer direkt ausgesprochen - das historische Kriterium, das die Forschung auf diesem Gebiet beherrscht hat, im Grunde ein ethnologisches, rassenkundliches gewesen und geblieben ist. Die Eigentümlichkeiten der römischen Kunst wurden immer wieder auf ein ethnisches Kriterium zurückgeführt, das aber kein historisches ist. ... Alles übrige wird dann durch innerliche Formenentwicklung erklärt ..."Vgl. auch BRENDEL (wie Anm. 2), bes. 60-74, jedoch mit selbstverständlicher Zustimmung zu dieser Methode (bes. S. 65); speziell zu Kaschnitz von Weinberg BAŽANT (wie Anm. 4), 90-99.

${ }^{14}$ Bereits in Ansätzen: Enciclopedia Italiana 29 (1936) s. v. ritratto, 475 (E. STRONG); G. RoDENWALDT, Römische Reliefs. Vorstufen zur Spätantike, JDAI 55, 1940, 12-43; 
teil, als nicht alle den Relativismus Riegls zu teilen bereit waren. ${ }^{15}$ Bei aller Anerkennung der je eigenen Bedeutung der Kunstrichtungen verschiedener Zeiten oder ,Nationen' bestanden insbesondere diejenigen, die das Studium der Antike mit einem mehr oder weniger ausgeprägten pädagogischen Impetus verbanden, doch auf einem abschließenden Urteil, das bei der Mehrzahl der Forscher nach wie vor eindeutig zugunsten der klassischgriechischen Kunst ausfiel. Das Urteil Gerhard Rodenwaldts, eines der wichtigsten und einflußreichsten Forscher zur römischen Kunst, mag dies stellvertretend belegen:

„Wenn die positive Wertung der absoluten künstlerischen Leistung der Spätantike nicht mehr umstritten ist, so haben wir andererseits im Gegensatz zu der Relativierung aller Werte durch Riegls Konstruktion des Kunstwollens wiederum gelernt, eine Abstufung der Werte vorzunehmen und uns des besonderen Wertes bewußt zu werden, den die im engeren Sinne klassische Kunst der Griechen, von der Frühklassik der ersten Hälfte des fünften Jahrhunderts bis zur Zeit Alexanders des Großen, für die Gegenwart und Zukunft der europäischen Kunst besitzt. "16

P. H. V. BlanCKENHAGEN, Elemente der römischen Kunst am Beispiel des Flavischen Stils, in: Das Neue Bild der Antike II, Leipzig 1942, 313f.; später dann besonders einflußreich R. BIANCHI BANDINELLI, dazu s. u. Vgl. S. SchÖNE, G. Rodenwaldts Bewertung römischer Kunst - Einordnung in das Forschungskontinuum, WZBerlin 35.8, 1986, 668-672; mit Bezug auf die Porträtforschung: M. BERGMANN, Studien zum römischen Porträt des 3. Jhs. n. Chr., Bonn 1977, 5-18 und BAŽANT (wie Anm. 4), 50-115.

${ }^{15}$ Betont wertneutral aber z.B. R. KEKULÉ VON STRADONITZ, Strategenköpfe, APAW, Berlin 1910, 4: "Wir werden uns daran gewöhnen müssen, wie es in der modernen Kunstgeschichte geschieht, so auch für die antike die Bildnisse als Dokumente künstlerischer und kunstgeschichtlicher Art anzuerkennen, künstlerische und kunstgeschichtliche Dokumente, die den Vorzug haben können, ein besonderes geschichtliches und persönliches Interesse auf sich zu vereinigen, die aber, sogar auch um der historischen Gerechtigkeit selbst willen, vor allem und zuerst kunstgeschichtlich zu betrachten sind." Vgl. auch F. MATZ (Wesen und Wirkung der augusteischen Kunst, Welt als Geschichte 4, 1938, 191-234, hier 191), der die ,epochale Bedeutung der augusteischen Werke“ in ,ihre[r] Eigenschaft als Mittler zwischen der Welt der Antike und der Spätantike, und ihre[r] Bedeutung für die ganze folgende abendländische Entwicklung überhaupt" betont. „Erst damit ist nun die Erörterung über diese Dinge auf die Ebene erhoben, die allein für alle römischen Erscheinungen die angemessene ist, auf die historische." (Hervorhebungen im Original) - eine Einschätzung, welche andererseits seiner ästhetischen Präferenz für die griechische Kunst nicht entgegensteht.

${ }^{16}$ G RoDENWALDT, Zur Begrenzung und Gliederung der Spätantike, JDAI 59/60, 1944/45, 81-87, hier 81, Hervorhebung B.E.B.; vgl. auch DERS., Zur Kunstgeschichte der Jahre 220 bis 270 , JDAI 51, 1936, 82-113, hier 110 und 112; „Es ist trotz aller neuen, fesselnden und bedeutenden künstlerischen Erscheinungen eine Zeit, die, gemessen an den höchsten Werten der Antike, eine Periode des Verfalls ist. Es war ein für seine Zeit 
Während die Suche nach den „höchsten Werten der Antike ${ }^{\text {¿17 }}$ diese Klassischen Archäologen durchaus mit den Interessen der Werteforschung der Nachbardisziplinen verband, so macht doch die Tatsache, daß man diese "höchsten Werte" allein bei den Griechen - und dort vorzugsweise in der Klassik - verwirklicht sah, deutlich, daß es zur Werteforschung der Latinistik kaum Verbindungen geben konnte. Vielmehr macht sich hier der Einfluß Werner Jaegers und des sog. Dritten Humanismus bemerkbar, der auch die ,römischen Archäologen ' nicht unberührt ließ. ${ }^{18}$ Was Teile der Latinistik und Alten Geschichte in den römischen Wertbegriffen suchten und zu finden glaubten, nämlich ewige Werte und Wahrheiten, fand die Klassische Archäologie, sofern sie sich als Kunstgeschichte begriff, ausschließlich in der griechischen Kunst. ${ }^{19}$

\section{Historische Ansätze in der römischen Archäologie in der ersten Hälfte des 20. Jahrhunderts}

Die zweite, weit weniger prominente Richtung dagegen war stärker an den Inhalten der Darstellungen interessiert und suchte die römische Kunst als historische Quelle zu nutzen. Hier hätten sich grundsätzlich Anknüpfungspunkte zur Werteforschung ergeben können, doch verstand und untersuchte

heuristisch wertvoller, aber verhängnisvoller Irrtum A. Riegls, daß er mit der Theorie des Kunstwollens eine Relativität aller kunstgeschichtlichen Werte proklamierte, die bis heute noch Anhänger findet." Siehe auch MARCHAND (wie Anm. 7), 333-335 mit Zitaten aus Rodenwaldts Korrespondenz; dazu G. KOCH, H. SICHTERMANN, Römische Sarkophage. Handbuch der Archäologie, München 1982, 15 mit Verweis auf ähnliche Äußerungen von F. Gerke, F. Matz, H. v. Schönebeck u. a. in Anm. 15; BoRBEIN (wie Anm. 2), bes. 196198; siehe weiterhin M. FRANZ, Denkstil und Kunstbegriff bei Gerhard Rodenwaldt, WZBerlin 35.8, 1986, 637-643; SCHÖNE (wie Anm. 14), 670f.

${ }^{17}$ Siehe RODENWALDT, Zur Kunstgeschichte (wie Anm. 16).

${ }^{18}$ Zum Dritten Humanismus und Werner Jaeger siehe u. a. MARCHAND (wie Anm. 7), 302-340; hier 321f. zur Beteiligung Rodenwaldts an der maßgeblich von Jaeger beförderten Gründung der Zeitschrift „Die Antike“, 333-335 zu Rodenwaldts Übereinstimmung mit Jaeger; G. BRANDS, „Zwischen Island und Athen“, in: B. BROCK, A. PREISS (Hgg.), Kunst auf Befehl?, München 1990, 103-136, bes. 118-120; zur Wirkung Stefan Georges siehe SCHEFOLD (wie Anm. 7).

${ }^{19}$ Weitere Nachweise siehe auch im Folgenden. - Diesen wichtigen Aspekt der deutschen Forschungsgeschichte weiter za verfolgen, ist hier nicht der Ort. Es ist jedoch klar, daß die Vorliebe für das Griechische alles andere als unideologisch war. Zur Instrumentalisierung der griechischen Kunst im Nationalsozialismus, die nicht zuletzt auf die bereits von Winckelmann formulierte These der ,Wesensverwandtschaft von Griechen und Deutschen rekurrierte (vgl. auch Rodenwaldt, unten S. 56), siehe BRANDS (wie Anm. 18). 
man die Historizität der fraglichen Denkmäler selten im weiteren Rahmen römischer politischer Konzepte, Ideale und Ideologien, sondern meist in einem ganz punktuellen Sinne: die Porträts als objektive Wiedergabe der zufälligen individuellen Physiognomie und Persönlichkeit, die Staatsreliefs als Darstellungen einzelner Episoden der Ereignisgeschichte, deren Kohärenz im Sinne eines Wertesystems zwar nicht gänzlich unbemerkt blieb, aber lange Zeit kaum der Untersuchung für wert befunden wurde.

Sofern man sich überhaupt mit den Inhalten der Darstellungen auf Reliefs und Reliefzyklen öffentlicher Monumente auseinandersetzte, führte man somit meist die Fragestellungen des 19. Jhs. fort, die auf der Annahme beruhten, die Reliefs seien Dokumente historischer Einzelereignisse, aus denen man sogar in den schriftlichen Quellen nicht überlieferte Informationen wie etwa den genauen Verlauf der Kampagnen der Dakerfeldzüge Trajans gewinnen könne. ${ }^{20}$ Ansonsten erkannte man zwar, daß bestimmte Themen sich immer wiederholten und konstatierte die Tatsache, daß dies auf eine besondere Bedeutung dieser ,Riten ' für den römischen Staat bzw. den Kaiser schließen lasse. Doch spielte diese Tatsache in der Forschung selten eine Rolle, sondern die Zusammenstellungen wurden vielmehr dazu genutzt, bei gleichem Thema stilistische Entwicklungen und Veränderungen nachzuweisen und zu erklären. ${ }^{21}$

Eine Ausnahme stellen Teile der Arbeiten Gerhard Rodenwaldts dar. In einem Aufsatz von 1935, der später geradezu ein Schlüsseltext einer neuen, am Politischen interessierten Römischen Archäologie werden sollte, behandelt Rodenwaldt u. a. die sog. Feldherren- oder Feldherren-Hochzeitssarkophage, eine Gruppe von Sarkophagen antoninischer Zeit, die mit geringen Variationen vier Szenen mit immer derselben Hauptperson zeigen. ${ }^{22}$ Auf

${ }^{20}$ M. BERgmANN, Zur Forschung über die Traians- und Marcussäule von 1865 bis 1945, in: E. GABBA, K. Christ (wie Anm. 2), 201-224, bes. 203-212. Vgl. L. CURTIUS, Der Geist der römischen Kunst, Die Antike 5, 1929, 187-220, hier 202f.: „Die römische Kunst ist immer faktisch. Immer sucht sie den einzelnen geschichtlichen Akt auf, die Reliefs der Traians- und der Marcussäule illustrieren Kriegszüge tagebuchartig, immer ist der Kaiser in die Szene verflochten, der erste diensttuende Soldat." Siehe außerdem G. RODENWALDT, Kunst um Augustus, Berlin 1942 (hier zitiert nach dem Ndr. Berlin 1988; erstmals in kürzerer Fassung: Die Antike 13, 1937, 155-196), 44 (zur Ara Pacis im Gegensatz zum Parthenonfries) sowie noch F. J. HASSEL, Der Trajansbogen in Benevent, ein Bauwerk des römischen Senats, Mainz 1966.

${ }^{21}$ Vgl. z. B. G. RodenwaldT, Ara Pacis und San Vitale, BJ 133, 1928, 228-235; O. BRENDEL, Immolatio Boum, MDAI(R) 45, 1930, 196-226, hier 217: „GewiB ist das Motiv im Lauf der Zeit ein Topos geworden, eine landläufige Tradition der römischen Bildhauerateliers, immer wieder hervorgeholt, wo es eben Stieropfer darzustellen gab.“

${ }^{22}$ G. RODENWALDT, Über den Stilwandel in der antoninischen Kunst, APAW 3, Berlin 1935 . 
einem Sarkophag in Frascati findet sich links die Darstellung einer Schlacht gegen Barbaren, es folgt eine Szene, in der einem Feldherrn gefangene Barbaren zugeführt werden, dann eine Opferszene und schließlich ein Ehepaar im Handschlag, eine Darstellung, die wegen des Hymenaios mit Fackel auf die Hochzeit der Eheleute bezogen wird. Während man diese Szenen zuvor im engeren Sinne biographisch als Darstellungen aufeinander folgender Lebensstadien verstanden hatte und über die Leserichtung (von rechts nach links oder umgekehrt) stritt, erkannte Rodenwaldt die „typische und symbolische Bedeutung " der Darstellungen, ${ }^{23}$ welche die Tugenden des Grabherrn feiern: virtus, clementia, pietas und concordia, also jene Tugenden, die auf dem clupeus virtutis des Augustus verzeichnet waren und die Rodenwaldt als die „vier römische[n] Kardinaltugenden“ bezeichnet. ${ }^{24}$ Von Werten ist hier jedoch nirgends die Rede und für die Begrifflichkeit beruft er sich auch nicht auf historische oder philologische Arbeiten, sondern auf numismatische, welche ikonographisch ähnliche, inschriftlich bezeichnete Darstellungen auf Münzen behandeln. Der Rest der Arbeit ist stilistischen Fragen gewidmet und von den Tugenden selbst wird nur die clementia etwas näher erläutert - wie in seinen anderen Untersuchungen zur römischen Kunst ganz aus der Perspektive der griechischen. Im Gegensatz zur „naiven griechischen Humanität“, die „mehr ist als Ritterlichkeit, die gesellschaftliche Tugend einer Adelsschicht", sei im Akt römischer clementia immer die Demütigung des Unterlegenen sichtbar. „Unser Gefühl ist, darin den Griechen verwandt, bei der Schilderung des Sieges von dem der Römer verschieden."25 Die „ethische Gesinnung" der Griechen und der griechischen Kunst sei eine „humanistische“, wogegen „[d]em Römer ... das menschliche Mitempfinden mit dem Besiegten fern [lag]; nichts kennzeichnet ihn besser als die Institution des Triumphes, die mitleidlose Schaustellung des Sieges. ...Es äußert sich hier ein Grundzug römischen Wesens, den die Römer nięmals zugunsten des griechischen Humanismus aufgegeben haben. ${ }^{\star 26}$

Ähnliches beobachtet man in seiner Kunst um Augustus. Hier bemüht Rodenwaldt durchaus Topoi wie die auctoritas des Kaisers und meint: „Der Wert der römischen Geschichte als der Lehrmeisterin politisch-geschichtlichen Denkens ist unumstritten." Wenngleich er deutlich zum Ausdruck

${ }^{23}$ Ebd. 2.

${ }^{24}$ Ebd. 6.

${ }^{25}$ Ebd. $7 f$.

${ }^{26}$ G. RoDENWALDT, Der Belgrader Kameo, JDAI 38, 1922, 17-38, Zitate S. $24 \mathrm{f}$. 
bringt, daß die Geschichte nicht sein eigentliches Gebiet ist, ${ }^{27}$ ist sich Rodenwaldt der politischen Seite der römischen Kunst und des Potentials bewußt, das darin für zeitgenössische Aktualisierungen lag. Doch im gleichen Zusammenhang, in dem er einmal von den „ewigen Werten Roms“ spricht, negiert er diese zugleich als etwas spezifisch Römisches:

„Für den Römer der Epoche Mussolinis ist das Verhältnis zur Kunst des "Augustus wie zur römischen Kunst kein Problem. ... Uns rufen die Römerbauten auf deutschem Boden die Erinnerung an Kampf und Fremdherrschaft wach. Der Begriff Rom ist für uns mit Erinnerungen belastet, deren politische Bedeutung uns nicht immer leicht den Zugang zu den ewigen Werten Roms finden läßt. Dagegen liegt das Griechentum für uns in einer Sphäre, die jenseits der Parteien Haß und Gunst ist." ${ }^{\text {(28 }}$

In der Statue des Augustus von Prima Porta sieht er nicht wie manche seiner Kollegen ein Charakterbild der wahren Persönlichkeit des Herrschers, sondern ein politisches Bild des "Mann[es], den die Welt brauchte.“ Doch wer in der folgenden Charakterisierung ,ewige römische Werte“ erwarten sollte, fände sich enttäuscht:

„Er war der Ordner eines Chaos, der Friedebringer für eine vom Krieg "erschöpfte und zerrissene Menschheit, der Gründer einer neuen Antike. Er vereinigte die höchste Intelligenz mit einem realpolitischen Taktgefühl ohnegleichen für materielle und geistige Mächte und einem auf lange Sicht handelnden unbeirrbaren Willen. Er war stark genug, um, wo es not tat, verzichten zu können. Er fühlte sich bewußt als Römer und hatte ein natürliches und sicheres Empfinden für Würde. ${ }^{629}$

Das Bild der ,großen Persönlichkeit', das hier gezeichnet wird, sieht den ,unbeirrbaren Willen' und die ,Würde` bezogen auf Friedensstiftung, Intelligenz, Taktgefühl und Verzicht! Mehr noch, Augustus gerät bei ihm geradezu zu einer tragischen Figur - und es ist eben dies, was ihn in den Augen Rodenwaldts sympathisch macht:

„Der Weg zur Freude an der augusteischen Kunst ist mühevoll, weil es nicht leicht ist, sich für die Persönlichkeit des Augustus zu erwärmen. Auch der Lebende hat langsam und spät die Herzen der zeitgenössischen Welt erobert. Es fehlt seiner Gestalt alles Strahlende, Heldische, Mit-

${ }^{27}$ Er fährt nämlich unmittelbar fort: „Aber was ist uns römische Kunst? ... Sind es auf dem Gebiet der bildenden Künste nicht allein die Griechen, auf die wir den Blick wenden sollen?": RODENWALDT (wie Anm. 20), 6.

${ }^{28}$ RODENWALDT (wie Anm. 20), 7.

${ }^{29}$ RODENWALDT (wie Anm. 20), 14. 
reißende. ... Erst die Einsamkeit und Tragik seines späteren Lebens bringt uns den Menschen näher, dem weder Schuld noch Leid erspart geblieben ist. “30

Von hier aus ist es nur ein kleiner Schritt zu Ludwig Curtius, dessen Auffassung von der römischen Kaiserzeit im allgemeinen in seiner Beschreibung eines Mädchenporträts kulminiert: „Die Trauer, die ihren Blick umflort, gehört zu dem Ernst, der die Welt erfüllt, seit sie römisch geworden ist. ${ }^{\text {“31 }}$ Das ,Heldische“ und ,Strahlende‘ ist wie alle ewigen Werte mit den Griechen untergegangen. ${ }^{32}$

Die meisten Gelehrten - darunter auch Curtius - sahen in den römischen Porträts jedoch keine politischen Monumente, sondern unterstellten Authentizität und Exaktheit in der Schilderung der individuellen Physiognomie bzw. der Persönlichkeit, des Charakters und ,Wesens' des Dargestellten. $^{33}$ Psychologisierende Deutungen der Physiognomien sollten

${ }^{30}$ RODENWALDT (wie Anm. 20), 14; vgl. auch seinen düsteren Kommentar S. $5 f$.

${ }^{31}$ Zitiert nach SCHEFOLD (wie Anm. 7), 19; vgl. auch L. CURTIUS (wie Anm. 20), bes. 206, wo der Reliefstil Ausdruck des betrüblichen Zustands der römischen Welt ist. Wenn seinen - freilich sehr eigenwilligen - Ausführungen zur römischen Tugend der virtus und der constantia oder zum römischen „Reichsbewußtsein" durchaus eine gewisse Begeisterung abzulesen ist, so betont er doch ausdrücklich das spezifisch Römische an ihnen und ist weit entfernt davon, ihnen universellen Wert zuzuschreiben. Von bleibendem Wert ist auch für Curtius einzig die griechische Kultur, daher schließt er seine Ausführungen in „Das Antike Rom" (Wien 1944), 7-27: „Ist es richtig, was Hegel in seinen Vorlesungen über die Philosophie der Weltgeschichte von der römischen Welt sagt: ,Rom hat das Herz der Welt gebrochen'? Das Herz der Welt war griechisch. Und dies Herz hat Rom der Welt bewahrt."

${ }^{32}$ Der Vollständigkeit halber sollte man jedoch hinzufügen, daß an besagter Stelle (s. o. S. 57) neben Alexander auch noch Caesar als strahlender Held genannt wird. Es wird hier deutlich, was an dieser Stelle nicht weiter ausgeführt werden kann, daß Archäologen wie Rodenwaldt und Curtius keineswegs unideologisch und auch manchen Ideen des Nationalsozialismus nicht abgeneigt waren. Insbesondere die als Ausdruck des nationalen Selbstbewußtseins aufgefaßten großen Bauten der römischen Antike wurden in positivem Sinne mit den Baumaßnahmen des ,Dritten Reiches' verglichen, siehe u. a. RODENWALDT (wie Anm. 19), 7f.; DERS., Römische Staatsarchitektur, in: H. BERVE, Das neue Bild der Antike II, Leipzig 1942, 356ff.; DERS., Griechisches und Römisches in Berliner Bauten des Klassizismus, Berlin 1956 ( $=$ Rede vor der Preussischen Akademie der Wissenschaften 1945); dazu BORBEIN (wie Anm. 2), bes. 193-195. Zu Curtius mit Nachweisen R. FABER, Humanistische und Faschistische Welt, Über Ludwig Curtius (1874-1954), Hephaistos 13, 1995, 137-186, sowie zur ideologischen Seite des Dritten Humanismus oben Anm. 18.

${ }^{33}$ Vgl. z. B. A. FURTWÄNGLER, Bronzekopf, des Kaisers Maximin im k. Antiquarium in München, MüJb 1, 1907, 8-17; R. WEST, Römische Porträt-Plastik I, München 1933, 9 und die Anwendung dieser Maxime passin;; L. CuRTıUS, Physiognomik des römischen 
diesen Charakter der Dargestellten entschlüsseln. ${ }^{34}$ Zum einen ging es dabei um den Individualcharakter einzelner Protagonisten des antiken Weltgeschehens, zum anderen aber auch um Volkscharaktere und deren - meist wertende - Unterscheidung. Gelegentlich fiel beides zusammen, wie bereits Adolf Furtwänglers 1907 erschienener Kommentar zu einẹm Bronzekopf des Maximinus Thrax im Münchner Antiquarium illustrieren mag:

„Es war offenbar eine rein nordische germanische Schönheit, die den Gotenabkömmling auszeichnete. Unser Porträt ... bestätigt die Überlieferung; dieser Kopf ist gänzlich unrömisch, in Form und Ausdruck; noch mehr als von eigentlichen Römertypen ist er aber von jenen orientalisierenden Typen verschieden, die unter den Porträts der späteren Kaiserzeit eine so große Rolle spielen. Dagegen sind die großen offenen Züge des Mannes offenbar germanischer Art; es ist der gotische Vater, der aus ihnen spricht. Mich erinnern diese Züge immer wieder an Personen rein deutscher Abkunft, die ich kenne. Was vor allem aus diesen Zügen spricht, ist ein treues, ehrliches, gerades Wesen; so wird uns auch Maximin geschildert als ein Mann von wilder, stolzer Kraft, doch aber treu und gerecht ...; das war germanisches Wesen." usw. ${ }^{35}$

Dieselben Eigenheiten des Porträts, die Furtwängler zu seiner Charakterstudie verleiten, hatte Riegl für die Zeit des mittleren 3. Jhs. im allgemeinen in Anspruch genommen ${ }^{36}$ und bereits Wickhoff hatte vor der physiognomischen Methode mit dem Hinweis gewarnt, die römischen Porträts seien

Porträts, Die Antike 7, 1931, 226-254 (hier 234: die Porträtkunst hat die "Absicht naturalistischer Objektivität" ) und in diesem Beitrag Anm. 42. L. Curtius sucht dagegen sogar, die ,besseren" Porträts bestimmten Meistern zuzuweisen: siehe seine "Ikonographische[n] Beiträge zum Porträt der römischen Republik und der julisch-claudischen Familie I-XIII" in den MDAI(R) 47, 1932 bis 56, 1945. Gerade in der Erfassung der Persönlichkeit wurde auch die künstlerische Qualität gesehen: siehe zum problematischen Status der Porträtkunst als künstlerisches Genre im 19. Jh. generell R. EITELBERGER VON EDELBERG, Das Porträt, in: Gesammelte Kunsthistorische Schriften III, Wien 1884, 189-220, und BAŽANT (wie Anm. 4), 23-28 und 43f.

${ }^{34}$ BAŽAANT (wie Anm. 4), 49-51. Zu den Anfängen und Grundlagen dieser psychologisierenden Methode siehe L. GIULIANI, Bildnis und Botschaft, Frankfurt a. M. 1986, bes. 25-51.

${ }^{35}$ FURTWÄNGLER (wie Anm. 33), 15f., zustimmend zitiert von HEKLER (wie Anm. 12), XLV. Der Kopf ehemals im Antiquarium München, dann Glyptothek Nr. 524, heute München, Bayerisches Nationalmuseum Inv. 35/386: H. B. WIGGERS, M. WEGNER, Caracalla bis Balbinus, Berlin 1971, 227. Ironischerweise galt dieser Bronzekopf bis zu Furtwängler als moderne Kopie und tut dies seit M. DELBRÜCK, Spätantike Kaiserporträts, AA 1933, 758, auch zu Recht wieder. - Zu Furtwängler siehe auch BAŽANT (wie Anm. 4), 77f.

${ }^{36}$ RIEGL, Kunstindustrie (wie Anm. 10), 132 und 208. 
in erster Linie künstlerischer Ausdruck, nicht exakte Schilderung von Physiognomien. ${ }^{37}$ Doch finden sich vergleichbare Analysen nicht nur während der gesamten Zeit bis zum Zweiten Weltkrieg, sondern die physiognomische Methode war - wenn auch nur noch selten mit rassistischen Anklängen, sondern meist auf die privaten Charaktereigenschaften der Dargestellten fokussiert - bis in die 60er Jahre verbreitet. ${ }^{38}$ Heckler, ein Schüler Furtwänglers, suchte sie mit dem Hinweis zu rechtfertigen, ein Porträt sei sowohl durch den Stil geprägt als auch durch die Person des Dargestellten; da der Stil aber rein griechisch sei, müßten die Abweichungen vom griechischen Porträt durch die Person des Dargestellten und die ,Ethik ${ }^{\star}$ der Römer bestimmt sein, ${ }^{39}$ wogegen Delbrück die Übereinstimmung zwischen Stil und Charakterzeichnung betonte. ${ }^{40}$ Während der 30er und 40er Jahre des 20. Jhs. war die physiognomisch-psychologisierende Methode in Deutschland allgemein akzeptiert, wie Arbeiten von Hekler, West, Möbus und insbesondere von Ludwig Curtius, einem weiteren Schüler Furtwänglers, belegen. ${ }^{41}$ Der historische Erkenntniswert sollte entweder in der Einfühlung in die römische Kultur und in die menschliche Natur im

${ }^{37}$ WICKHOFF (wie Anm. 9), 75. Wickhoffs Ansatz wurde insbesondere von Kaschnitz von Weinberg weiterverfolgt; dazu BAŽANT (wie Anm. 4), 90-99; ähnlich O. VESSBERG, Studien zur Kunstgeschichte der römischen Republik, Lund u. a. 1941, 115-168.

${ }^{38}$ Zur Kritik GIULIANI (wie Anm. 34), passim; siehe aber schon W. H. Gross in seiner Rezension der heftig psychologisierenden Arbeit von H. v. HEINTZE (Die antiken Porträts in SchloB Fasanerie bei Fulda, Mainz 1968), Gymnasium 77, 1970, 152-154, bes. 153; DERS., Caligula oder zulässige und unzulässige Interpretationen eines römischen Herrscherbildes, in: W. SCHINDLER ( $\mathrm{Hg}$.), Römisches Porträt. Wege zur Erforschung eines gesellschaftlichen Phänomens. Wissenschaftliche Konferenz 12.-15. Mai 1981, WZBerlin 31.2-3, 1982, 205-207. Noch H. SICHTERMANN (Der Themistokles von Ostia. Seine Wirkung in fünfundzwanzig Jahren, Gymnasium 71, 1964, 348-381, hier 368) erkennt im Porträt des Themistokles dessen halb-thrakische Abstammung.

${ }^{39}$ HEKLER (wie Anm. 12), 28: „Ethische Färbung und Nüchternheit des Ausdrucks werden demnach an diesen Porträtköpfen durch die geistige und physiognomische Art des gesunden, kraftvollen, römischen Bauernstandes bedingt. Die Dargestellten sind treffliche Beispiele echter Römer; die Art der Darstellung hingegen ... ist durchaus griechisch." Dazu BAŽANT (wie Anm. 4), $78 \mathrm{f}$.

${ }^{40}$ R. DELBRÜCK, Antike Porträts, Bonn 1912, 19-22.

${ }^{41}$ HEKLER (wie Anm. 12); DERS., Römische Bildnisstudien, La critica d'arte 3, 1938, 91-96; G. MŐBUS, Vom Gesicht des Römers, Neue Jahrbücher für Antike und Deutsche Bildung 116, 1941, 297-304; R. WEST, Römische Porträt-Plastik I-II, München 1933/1944. Auch das Ausland fand an solchen Arbeiten Gefallen, wie die englische und französische Übersetzung von Heklers Monographie (1912 bzw. 1913) demonstrieren; weitere Bsp. in I. LOHMANN-SIEMS, Begriff und Interpretation des Portraits in der kunstgeschichtlichen Literatur, Hamburg 1972, 91 Anm. 149, und BAŽ́ANT (wie Anm. 4), 82. 
allgemeinen bestehen, ${ }^{42}$ oder aber in einer Bestätigung, Ergänzung oder Falsifizierung der antiken Überlieferung über die Protagonisten des Weltgeschehens. Hekler etwa sieht in den Porträts eine instruktive Bestätigung für die bei den antiken Historikern überlieferte, innere Zersetzung ' während der julisch-claudischen Epoche nach dem Tod des Augustus, während die Porträts des Philippus Arabs die Quellenlage auf willkommene Weise ergänzen: „Der falsche Blick und die Verdrießlichkeit des Ausdruckes erzählen viel mehr von der seelischen Beschaffenheit des dargestellten Kaisers, als die mangelhafte Überlieferung. Man erkennt in seinem Antlitz den geborenen Araber, der sich den Weg nicht mit mutiger Energie, sondern mit Hinterlist zu ebnen suchte. ${ }^{\text {“43 }}$ Oft wiederholten die Charakterisierungen der Dargestellten, sofern es sich um bekannte Persönlichkeiten handelt, diejenigen antiker (oder aber moderner ${ }^{44}$ ) Historiker. Daß dabei selbstverständlich auch Eigenschaften genannt wurden, die in der altertumswissenschaftlichen Werteforschung eine Rolle spielten, versteht sich fast von selbst, doch stellen Arbeiten, die ausdrücklich auf diese Forschungen Bezug nehmen würden, seltene Ausnahmen dar. Letztlich ist dies auch nicht verwunderlich, da man in den Bildnissen ja objektive Schilderungen von Aussehen und Charakter der Dargestellten sah. Die Vielfalt des realen Lebens spiegelte sich in der Vielfalt der Charaktere, und die Analysen fielen jeweils sehr individuell aus. ${ }^{45}$ Hinzu kam, daß die Porträts - und vor allem die künstlerisch bedeutsamsten - angeblich gerade die sonst verborgenen, negativen Züge der Dargestellten zum Ausdruck brachten, sei es, daß man

${ }^{42}$ CURTIUS (wie Anm. 33), 235f:: „Der Natüralismus unserer Porträts hingegen hat darin seine Besonderheit, daß seine Objektivität mit der Minusseite des Charakters, des Lebens rechnet, als ob sie der wesentliche Inhalt der Darstellung wäre. Diese Menschen stehen sozusagen im luftleeren Raum, sind nur sie selbst und nichts anderes, und der Zauber dieser Kunstwerke besteht in der Entzauberung des Menschen, in einer psychologischen Entschleierung, wie sie nie eine andere alte Kunst gewagt hat."

${ }^{43}$ HeKLER (wie Anm, 12), 35 bzw. 45; siehe auch LANCKOROŃsKi (wie Anm. 5), z. B. 11-13 zu Pompeius.

${ }^{44}$ Im Falle von Curtius hat L. GIULIANI (wie Anm. 34), 28 eine frappierende Übereinstimmung mit den Urteilen Mommsens über die betreffenden historischen Personen ausgemacht und darauf hingewiesen, daß die ,Methode' der spontanen ,Einfühlung“ notwendigerweise nur die eigenen Urteile und Vorurteile bestätigen kann (ebd. 44f.).

${ }^{45} \mathrm{~K}$. SCHEFOLD, Schöpfung und Erneuerung in Ludwig Curtius' Lebenswerk, MDAI(R) 82, 1975, 11-20, bes. 19: „So sehr ihn dabei die Kunde von der großen geschichtlichen Persönlichkeit reizte, nicht weniger wichtig war ihm die unendliche Vielfalt von Charakteren in ihrer irdischen Bedingtheit." Davon abgesehen richteten sich viele der Studien an ein breiteres Publikum, das man durch eine Sammlung möglichst unterschiedlicher Charaktere zu unterhalten suchte. 
diese Züge als persönliche Eigenschaften des Individuums ansah ${ }^{46}$ oder aber als Ausdruck ihrer Zeit. ${ }^{47}$

Eine Ausnahme stellen lediglich die völkischen bzw. rassistischen Aspekte dieser Untersuchungen dar, die die positiven wie negativen Vorurteile über verschiedene ,Nationen“ und ,Rassen' wiederholten, unter denen auch die ,hohen römischen Lebenswerte“ (Möbus) zu finden sind. Sie waren, wie schon das obige Furtwänglerzitat belegt, bereits seit der Jahrhundertwende ein geläufiger Teil von Porträtinterpretationen und keineswegs auf Sympathisanten der Nationalsozialisten beschränkt, wenngleich sie seit der Machtergreifung Hitlers.neuen Aufschwung erhielten. So war es durchaus üblich, in den republikanischen Porträts „die geistige und physiognomische Art des gesunden, kraftvollen, römischen Bauernstandes“ im Gegensatz zu den ,geistvollen, glänzend begabten und nervösen Griechen ${ }^{\text {c48 }}$ wieder zu erkennen, und wie man meinte, die ,nordische" Abstammung des Maximinus Thrax und seine mit dieser Abstammung verbundenen Tugenden in seinen Bildnissen zu finden, so konnte man auch die negativen Charaktereigenschaften eines Kaisers nordafrikanischer oder arabischer Herkunft aus seinem Bildnis ablesen. ${ }^{49}$ Gerhard Möbus untertitelt seine physiognomische Studie „Ein Beitrag zur Wesenskunde des Römertums" und setzt den seiner Meinung nach verfehlten Deutungen Curtius' seine eigene, völkische Interpretation entgegen:

„In ihrer Gestalt und Gestaltung stellt sich uns ein Menschenbild dar, gesteuert von einem wachen Verstande, beherrscht von einem gespannten Willen und nüchterner, angestrengter Zielstrebigkeit. Diese Züge, mag auch halb der eine, halb der andere stärker heraustreten, bestimmen unverkennbar das Bildnis des Römers. Schwer fallen uns bei ihrem Anblick römische Wertwörter in die Seele, wie gravitas, constantia, severitas; ihre harte Ernsthaftigkeit und grämliche Unbeschwingtheit macht die ange-

${ }^{46}$ Siehe das Zitat von Curtius (oben Anm. 42) sowie seine einzelnen Deutungen (wie Anm. 33), passim.

${ }^{47}$ Vgl. die Zitate von Hekler (oben S. 60-61) und Curtius (oben S. 57-58).

${ }^{48}$ HeKLER (wie Anm. 12), 30; siehe auch ebd. 31: „Der Hauptwert der republikanisch-römischen Porträts besteht demnach darin, daß sie die vorherrschenden ethischen Grundeigenschaften des römischen Bauernstandes in großartig erfaßten physiognomischen Variationen für alle Zeiten verewigt haben. Sie verkünden trotz der größten Mannigfaltigkeit in den physischen Daseinsformen mehr vom ethischen Rassencharakter als von den Konstellationen der persönlichen Psyche."

${ }^{49}$ HeKLER (wie Anm. 12), 42f. zu Septimius Severus und 45 zu Philippus Arabs. 
strengte Gerichtetheit und das nüchterne Zweckdenken des Römers lebendig und zugleich unvergeßlich. “50

Im Folgenden ist noch von anderen ,hohen römischen Lebenswerten“ die Rede und hier einmal wird ausdrücklich auf Richard Heinzes Werk „Vom Geist des Römertums" verwiesen. ${ }^{51} 1933$ verkündete Fritz Schachermayr, es sei die Hauptaufgabe der Altertumsforscher, eine kritische Scheidung des klassischen Erbes in seine nordischen und seine rassenfremden Komponenten vorzunehmen, ${ }^{52}$ und der Innsbrucker Althistoriker Franz Miltner unternahm den Vorstoß, in Rom ein "Rassekundlich-Historisches Institut" einzurichten. ${ }^{53}$ Dort sollten, in Ermangelung unmittelbaren ,Anschauungsmaterials' aus der Antike, u. a. die Porträts der reichen römischen Sammlungen nach physisch-antbropologischen und rassekundlichen Kriterien eingeordnet werden. ${ }^{54}$ Das Projekt wurde bei Kriegsausbruch zurückgestellt und nie verwirklicht - was Miltner noch 1952 zu bedauern scheint ${ }^{55}$-, aber

${ }^{50}$ MöBuS (wie Anm. 41), 302.

${ }^{51}$ R. HEINZE, Vom Geist des Römertums, Leipzig 1938; vgl. zu Heinze S. REBENICH, Römische Wertbegriffe: Wissenschaftsgeschichtliche Anmerkungen aus althistorischer Sicht (in diesem Band), bes. 29-30.

${ }^{52}$ F. SCHACHERMAYR, Die Aufgaben der Alten Geschichte im Rahmen der nordischen Weltgeschichte, Vergangenheit und Gegenwart 23, 1933, 589-600, bes. 599 (zitiert nach BAŽANT [wie Anm. 4], 83).

${ }^{53}$ V. LosEMANN, Nationalsozialismus und die Antike. Studien zur Entwicklung des Faches Alte Geschichte 1933-1945, Hamburg 1977, 132-139; BAŽANT (wie Ann. 4), 83; G. BINDER, Exkurs: „Augusteische Erneuerung" in der Archäologie 1933-1945, in: DERS. (Hg.), Saeculum Augustum III: Kunst und Bildersprache, Darmstadt 1991, 19-30, bes. $20 \mathrm{f}$.

${ }^{54} \mathrm{Vgl}$. die Forderung an das Deutsche Archäologische Institut in Rom, seine Untersuchungen auf die „Lebenszeugnisse des Germanentums" in Italien zu fokussieren, dazu K. JUNKER, Das Archäologische Institut des Deutschen Reiches zwischen Forschung und Politik. Die Jahre 1929 bis 1945, Mainz 1997; zusammenfassend DERS., Research under dictatorship: the German Archaeological Institute 1929-1945, Antiquity 72, 1998, 282292, bes. 298f. Andere waren bemüht nachzuweisen, daß die frühen römischen Kaiser "noch nordischen Blutes" gewesen seien, während später das „Rassenchaos" einsetze (W. BREWITZ, Die Entnordung der Römer, Volk und Rasse 9, 1936, 369-373, Zitate S. 369; siehe auch M. HESCH, Zur Auswirkung nordischer Rasse im Römertum der Zeitenwende, Rasse 4, 1937, 475f.; beide auf Grundlage von H.F. K. GÜNTHER, Rassengeschichte des hellenischen und des römischen Volkes, München 1929); dazu BINDER (wie Anm. 53), 19-30, bes. $21 \mathrm{f}$

${ }^{55}$ F. MILTNER, Zur Themistoklesherme aus Ostia, JÖAI 39, 1952, 70-75, hier 74f.: „Eine klare und umfassende Durcharbeitung des gesamten uns überlieferten Portrătmateriales unter ethnographischem Gesichtspunkt würde aber unser Wissen um manche Person nicht nur an wertvollen Einzelheiten bereichern, sondern es ließen sich zudem für 
mit ähnlichem Interesse versuchten Eugen Fischer und Gerhard Kittel in einer Untersuchung durch die Identifizierung von Judenporträts die Bedrohung durch das , Weltjudentum ${ }^{6}$ bereits in der Antike nachzuweisen. ${ }^{56}$

\section{Römische Archäologie als Geschichtswissenschaft - Paradigmenwechsel in den 60er Jahren}

In der Zeit unmittelbar nach dem Zweiten Weltkrieg beschränkte sich die deutsche Forschung zunächst fast ganz auf die scheinbar ideologiefreien und somit unverdächtigen kunstgeschichtlichen Aspekte der Disziplin. In den 60er Jahren erlebte die römische Archäologie jedoch einen ungeahnten Aufschwung, der einem regelrechten Paradigmenwechsel zu verdanken war, welcher die Disziplin erstmals zumindest thematisch in die Nähe zur Werteforschung der Nachbardisziplinen führte. Eine junge Generation von Wissenschaftlern, unzufrieden mit den traditionellen kunsthistorischen Ansätzen, die vielfach in die Aporie geführt hatten, und angeregt durch die allgemeine Politisierung der Gesellschaft und der Universitäten im besonderen, entdeckte für sich die politisch-ideologische und soziologische Seite der römischen Kunst und verstand die Archäologie neuerdings als eine Teildisziplin der Geschichtswissenschaft. ,Historische Reliefs' ${ }^{`}$ und Porträts, die zuvor fast ausschließlich unter stilistischen Gesichtspunkten und ohne Berücksichtigung ihrer antiken Kontexte untersucht worden waren, wurden nun als Träger von Botschaften in der gesellschaftlichen Kommunikation erkannt. ${ }^{57}$

manchen ohne Benennung auf uns gekommenen Kopf wichtige Anhaltspunkte für eine nähere Bestimmung gewinnen."

${ }^{56}$ E. FISCHER, G. KITTEL, Das antike Weltjudentum, Forschungen zur Judenfrage 7, Hamburg 1943; vgl. zu Fischer: N. C. LösCH, Rasse als Konstrukt. Leben und Werk Eugen Fischers, Frankfurt 1997. - Auch wenn unbestreitbar ist, daß die archäologischen physiognomischen Arbeiten sowohl ein Zeichen der Akzeptanz rassistischer und diskriminierender politischer Haltungen und Aktivitäten sind als auch ihren eigenen Beitrag dazu geleistet haben, so ist doch G. Binders Beobachtung zutreffend, daß die ausdrücklich und unmittelbar im Dienste der nationalsozialistischen Propaganda stehenden Arbeiten in der Art derjenigen von Fischer und Kittel nicht von Archäologen verfaßt wurden und der Ansto $\beta$ zu Unternehmungen wie dem Rassekundlichen Institut und den Versuchen, das ,nordische Blut ' der frühen römischen Kaiser nachzuweisen, gleichfalls nicht aus den Reihen der Porträtforscher kam; vgl. ähnlich MARCHAND (wie Anm. 7), 304.

${ }^{57}$ Zum Interesse der 68er Generation an Politik und Machtkonstellationen siehe BianCHI BANDINElli (wie Anm. 8), 13 und 141; T. HölschER, Augustus und die Macht der Archäologie, in: La révolution romaine après Ronald Syme. Bilans et per- 
Anregung fand diese Generation vor allem in den Schriften des Marxisten Ranuccio Bianchi Bandinelli, der bereits seit den 50er Jahren für eine soziologische Deutung der römischen Kunst plädierte. ${ }^{58}$ Wie einige deutsche Forscher vor $\mathrm{ihm}^{59}$ unterschied er einen volkstümlichen und einen klassizistischen Stil in der römischen Kunst, sah diese jedoch ausdrücklich als klassenspezifisch an. Die ,patrizische' und die ,plebejische Kunst' seien in der republikanischen Zeit entstanden und hätten während der gesamten Kaiserzeit im Widerstreit gestanden. ${ }^{60}$

In der Porträtforschung griff vor allem Paul Zanker mit seinen ersten Arbeiten zum Porträt der Republik den Ansatz Bianchi Bandinellis auf. Während letzterer sein Klassenparadigma jedoch universal auf die gesamte römische Kunst anwandte, konkretisierte, flexibilisierte und differenzierte Zanker die Thesen. In der Porträtkunst der späten Republik identifizierte er zwei Hauptströmungen, deren eine er aus dem ,psychologischen Realismus ${ }^{6}$ der hellenistischen Porträts herleitete und mit den herrschenden Schichten Roms in Verbindung brachte, und deren andere, ,veristische ${ }^{\prime}$ er auf die ,Mittelschicht ${ }^{6}$ bezog. ${ }^{61}$ Im Unterschied zu Bianchi Bandinelli sah er

spectives. Entretiens sur l'antiquité classique, Vandoeuvres 6 - 10 septembre 1999, Genf 2000, 237-273.

${ }^{58}$ R. BIANCHI BANDINELli (wie Anm. 8), 10 und passim; DERS. (wie Anm. 13); DERS., Roma, L'arte Romana nel centro del potere dalle origine alla fine del II secolo d. C., Mailand 1969 (englische und deutsche Übersetzung 1970); DERS., Roma. La fine dell'arte antica. L'arte dell'impero Romano da Settimio Severo a Teodosio I, Mailand 1970 (englische und deutsche Übersetzung 1970 und 1971), je mit Verweis auf erste frühere Arbeiten.

${ }^{59}$ Ironischerweise beruft sich Bianchi Bandinelli für seine Forschungen ausdrücklich auf deutsche Anregungen, welche aber in Deutschland selbst in ihrem Potenzial erst spät wahrgenommen wurden: siehe etwa I. SCOTT RYBERGs (Rites of the State Religion in Roman Art, New Haven 1955, 209 mit Anm. 17) Kritik (mit ausdrücklichem Hinweis auf Rodenwaldt): "The firmly entrenched misconception that ,historical" character of the content implied realistic accuracy in the documentary sense has not even yet been fully removed." $\mathrm{Zu}$ den frühen deutschen Ansätzen in dieser Richtung siehe den Forschungsüberblick bei G. KOEPPEL, The Grand Pictorial Tradition of Roman Historical Representation during the Early Empire, in: ANRW 12.1 (1982), 508-511; und Anm. 4 in diesem Beitrag.

${ }^{60}$ R. BIANCHI-BANDINELLI, Sulla formazione del ritratto romano, in: DERS., Archeologia e cultura, Mailand 1961, 172-188 = Società 13, 1957, 18ff.; DERS. (wie Anm. 13); DERS., L'Origine del Ritratto in Grecia e in Roma, Rom 1959; DERS, Archeologia e Cultura, Mailand 1961; DERS., Roma. L'arte romana nel centro del potere, Mailand 1969; dazu BAŽANT (wie Anm. 4), 103-105.

${ }^{61}$ P. ZANKER, Grabreliefs römischer Freigelassener, DAI 90, 1975, 267-315; DERS., Zur Rezeption des hellenistischen Individualporträts in Rom und in den italienischen 
diese Zuordnungen jedoch nicht als einen beinahe ontologisch an die sozialen Schichten gebundenen und wie diese im ständigen Wettstreit stehenden Dualismus an, sondern als eine gezielte Wahl unter bestimmten historischen Voraussetzungen. Damit war nun aber ein neuer Weg zur Interpretation römischer Porträts insgesamt eröffnet, den wiederum Zanker zuerst am Augustusporträt aufzeigte. In einer 1973 erschienenen Studie interpretierte er den damals noch Actiumtypus, heute meist Octavianstypus genannten Bildnisentwurf, der den noch jungen Octavian darstellt, auf der Grundlage seiner formalen und ikonographischen Verankerung in der Tradition des Alexanderporträts und der hellenistischen Herrscher im Sinne einer Demonstration von Sieghaftigkeit und kriegerischer virtus, während er den im Jahr 27 v. Chr. oder bald danach geschaffenen sog. Primaporta-Typus, der auf klassisch-griechische Formen zurückgreift, im Anschluß an Quintilians Beurteilung des Doryphoros als Verkörperung des Ideals ruhiger Erhabenheit und des Titels Augustus, als Bild eines vir gravis et sanctus, deutete. ${ }^{62}$ Aus der Erkenntnis, daß der Habitus des Octaviansporträts auch bei anderen Bildnissen der späten Republik zu beobachten ist, schloß er zudem: „Es wäre durchaus denkbar, daß in ihnen die politische Grundhaltung einer bestimmten Gruppe zum Ausdruck kommt. “63

Dies war in der Tat richtungweisend für die weitere Porträtforschung, in der sich das soziologisch-ideologische Paradigma nun allgemein durchsetzte. Während die Gelehrten der ersten Jahrhunderthälfte nur dem griechischen Porträt eine über das Zufällig-Individuelle hinausgehende Bedeutung zugestanden, ${ }^{64}$ stellte man nun fest, daß römische Porträts nicht unbedingt objektive Abschilderungen von Physiognomie und Charakter des Dar-

Städten, in: DERS. (Hg.), Hellenismus in Mittelitalien. Kolloquium in Göttingen vom 5. bis 9. Juni 1974, Göttingen 1976, 581-605.

${ }^{62}$ P. ZANKER, Studien zu den Augustus-Porträts. I. Der Actium-Typus, Göttingen 1973; DERS., K. VIERNEISEL, Die Bildnisse des Augustus, Herrscherbild und Politik im kaiserlichen Rom, München 1979; DERS., Prinzipat und Herrscherbild, Gymnasium 86, $1979,353-368$.

${ }^{63}$ Ebd. 38.

${ }^{64}$ HEKLER (wie Anm. 12), VIII: „Es ist wichtig zu betonen, daß die ersten Anregungen zu Porträtdarstellungen bei den Griechen, im Gegensatze zu den Ägyptern und Römern, nicht durch religiöse Bedürfnisse, sondern durch die Verehrung höchster menschlicher Eigenschaften, der körperlichen und geistigen Tüchtigkeit, gegeben wurden." Siehe noch B. SCHWEITZER, Die Bildniskunst der römischen Republik, Leipzig 1948, 137: „Denn jede autonome Plastik sammelt, auch im Bildnis, den allgemeinen Sinn, unter dessen erhellenden Schein sie ihren Gegenstand stellt; der römische Begriff der imago aber klammert sich an die einmalige Wirklichkeit des Dargestellten ... Römische Bildnisse sind Lebensdokumente des Einzelnen, der Familie, des Geschlechts, des Staates." 
gestellten sind, sondern ,Selbstdarstellung,, sein durch den Gesamthabitus zum Ausdruck gebrachtes - notwendigerweise positives - Selbstverständnis, sein auf zeitgenössische, allgemein akzeptierte Tugenden oder ,Werte' rekurrierendes, image ${ }^{6}{ }^{65}$ Zugleich war die ,Methode‘ unmittelbarer Einfühlung der Erkenntnis gewichen, daß zwischen Antike und Gegenwart eine unüberbrückbare Kluft lag, und daß man die Bildnisse daher nur aus ihrer eigenen Zeit heraus interpretieren konnte. „In other words: in the evaluation of Roman portraits the political and sociological standards of modern times were replaced by a reconstruction of the ancient Greek and Roman ones. ${ }^{\star 66}{ }^{66}$ Die Suche nach den ,Botschaften“ der Bildnisse machte nicht nur das Genre des Porträts für eine politisch interessierte Generation erneut interessant, sondern es bot auch - jedenfalls auf einer grundsätzlichen methodischen Ebene - eine Lösung für das bis dahin notorische Problem des stilistischen Pluralismus an. In ihrer im Wintersemester 1971/72 eingereichten und 1977 publízierten Dissertation zu den Porträts des 3. Jhs. deutete Marianne Bergmann z. B. den ,Realismus“ des Maximinus-ThraxPorträts als „Demonstration von soldatischer Tatkraft und Tüchtigkeit ..., die vielleicht weiter, z. B. zur ,cura imperii“ hin überhöht werden kann“, während sie den ,Klassizismus' der Prinzenporträts, z. B. des Maximus, mit Hinweis auf die beliebte Reversinschrift der Münzen, ,Spes publica', unter dem Aspekt der Thronfolgerschaft sah. ${ }^{67} 1982$ interpretierte Klaus Fittschen, wenn nicht die Porträts als solche, so doch die Anzahl der Bildnistypen der Faustina Minor als Ausdruck der Fecunditas Augustae. ${ }^{68}$ 1986 holte Luca Giuliani schließlich die bis dato eher implizit gefuihrte Methodendiskussion nach und unterzog vor allem die physiognomischen Deutungen einer systematischen Kritik. Zugleich war er bemüht, die politisch-ideologischen Deutungen auf eine sicherere methodische Grundlage

${ }^{65}$ Vgl. z. B. BERGMANN (wie Anm. 14), 15: „Dabei darf man wohl davon ausgehen, daB hinter einem Kaiserporträt in der Mehrzahl der Fälle eine positive Aussage, ein politisches Versprechen im weitesten Sinne stecken muB."

${ }^{66}$ BAŽANT (wie Anm. 4), 101. - Eine weitere wichtige Reaktion auf die Erkenntnis der Distanz zwischen Antike und Gegenwart war ein neuer Positivismus, der sich um die Datierung, Typenbestimmung und Identifizierung auf gesicherten methodischen Grundlagen bemühte und anerkanntermaßen die Grundlage für die interpretierenden Studien legte; siehe bes. die zahlreichen Arbeiten von Klaus Fittschen (grundsätzlich etwa K. FITTSCHEN, Zum angeblichen Bildnis des Lucius Verus im Thermen-Museum, JDAI 86, 1971, 214-252), aber auch den programmatischen Artikel von W. TRILLMICH, Zur Formgeschichte von Bildnis-Typen, JDAI 86, 1971, 179-213.

${ }^{67}$ BERGMANN (wie Anm. 14), 15f,

${ }^{68}$ K. FITTSCHEN, Die Bildnistypen der Faustina minor und die Fecunditas Augustae, Göttingen 1982. 
zu stellen, indem er Beschreibungen von Mimik und ,Pathognomik in den antiken rhetorischen Schriften auf mimische Grundformeln bezog, die sich - bei aller Individualität einzelner Köpfe - als eine Art Zeichensystem auch in den Porträts wieder finden. ${ }^{69}$

Mit dem neuen Interesse am Politischen verschob sich auch in der Interpretation der sog. historischen Reliefs - die man nun konsequenterweise Staatsreliefs zu nennen begann - der Schwerpunkt von einer ereignishistorischen zu einer Analyse politischer Leitbegriffe. Schon lange hatte man bemerkt, daß etwa die antoninischen Reliefs im Konservatorenpalast und am Konstantinsbogen oder diejenigen am Trajansbogen von Benevent dazu dienten, den Kaiser als vorbildlichen Herrscher vorzuführen. Auch hatte man gelegentlich Münzen zum Vergleich herangezogen und auf dieser Grundlage das zentrale Thema ermittelt. Vor allem der Schwede Per Gustaf Hamberg hatte bereits 1945 in einer wegweisenden Studie gefordert, bei der Untersuchung der Staatsreliefs solle es nicht um ,the description ... of the external appearance of events, but of their relation to the moral and religious foundations of the State, their historic importance in a profounder sense, seen against the background of the great contemporary conceptions of political thought" gehen. Die Reliefs teilte er in vier Gruppen ein, welche diese "moral-political conceptions" in unterschiedlicher Weise zum Ausdruck brächten: die allegorische, die symbolische, die illustrative und die anspielende ("allusive").$^{70}$ Allerdings hatten diese Arbeiten in Deutschland nie besondere Aufmerksamkeit erlangt, was wohl vor allem auf die genannte Fixierung der Forschung auf kunsthistorische Fragen im engeren Sinne zurückzuführen ist. Daneben scheint jedoch auch die feste Überzeugung eine Rolle gespielt zu haben, daß die Römer im Gegensatz zu den Griechen eben nicht an allgemeinen Werten und höheren Ideen, sondern an Geschichte - und das meinte immer Ereignisgeschichte - interessiert

${ }^{69}$ GiUliani (wie Anm. 34), passim. Die Aufnahme der Arbeit war jedoch zwiespältig. Während einerseits der systematische Zugang der Arbeit und die Aufgabe der Theorieabstinenz gelobt wurden, erschien die Kritik anderen inzwischen anachronistisch (siehe z. B. schon GROSS [wie Anm. 38]). Giulianis Vorschlag zur Methode wurde nicht nur als zu starr und schematisch angesehen, sondern er ließ sich mangels vergleichbarer Quellen auch nicht auf andere Epochen übertragen.

${ }^{70}$ P. G. HAMBERG, Studies in Roman Imperial Art with Special Reference to the State Reliefs of the Second Century, Uppsala/Kopenhagen 1945, hier 15; siehe aber auch E. STRong, Roman Sculpture, London 1907, 214-223; J. M. C. TOYNBEE, The Hadrianic School, Cambridge 1934; E. VON GARGER, Der Trajansbogen in Benevent, Berlin 1943; R. BRILliant, Gesture and Rank in Roman Art, New Haven, Conn. 1963. 
waren. ${ }^{71}$ Mit dem neuen Forschungsinteresse gerieten jedoch diese bisher wenig beachteten Beobachtungen ins Zentrum der Untersuchungen. Auch war man im Ausland schon länger an der politischen Seite der Staatsreliefs interessiert gewesen und hatte entsprechende Arbeiten vorgelegt, auf die sich die deutsche Forschung nun berufen konnte. ${ }^{72}$ Die erste größere deutsche Studie auf dem Gebiet war die 1965 in Heidelberg eingereichte Dissertation Tonio Hölschers zur victoria Romana, die unter anderem auch Staatsreliefs mit Szenen von profectio, adventus und Triumph ausführlich behandelt und gleich eingangs programmatisch formuliert:

„Die Kunst, um die es hier geht, ist Propaganda- und Repräsentationskunst. Sie dient der rühmenden Hervorhebung von Personen, Ereignissen oder Ideen, oft auch der Deutung oder Umdeutung politischer Vorgänge oder Situationen. Ihr Inhalt ist etwas völlig Unkünstlerisches, das sich eigentlich dem Auge und somit bildlicher Darstellung nicht erschließen kann: die ideologische Grundlage des römischen Staates, vor allem des Kaisertums. ${ }^{\text {"73 }}$

Unter derselben Prämisse entstanden in der Folge zahlreiche weitere Arbeiten, welche die römischen Staatsreliefs als politische Monumente und propagandistischen Ausdruck zentraler römischer Ideen interpretierten. 1972 vertraten Volker Michael Strocka und Klaus Fittschen erstmals die radikale These, daß bestimmte Monumente - hier der Quadrifrons in Lepcis Magna und der Trajansbogen von Benevent - ausschließlich allgemeine

${ }^{71}$ Vgl. z. B. die Bemerkungen Rodenwaldts zu Parthenonfries und Ara Pacis, dazu oben Anm. 20; J. SIEVEKING, Das römische Relief. FS Paul Arndt, München 1925, 1435; siehe außerdem G. KOEPPEL, Official State Reliefs of the City of Rome in the Imperial Age. A Bibliography, in: ANRW 12.1 (1982), 477-506, und DERS., The Grand Pictorial Tradition of Roman Historical Representation during the Early Empire, in: ebd. 507-535, bes. 508-511; siehe auch Scott Rybergs Kommentar zu Rodenwaldt (oben Anm. 59).

${ }^{72}$ Insbesondere HAMBERG (wie Anm. 70); SCOTT RYBERG (wie Anm. 59), passim; DIES,, Panel Reliefs of Marcus Aurelius, New York 1967; R. BRILLIANT, Gesture and Rank. The Use of Gesture to Denote Status in Roman Sculpture and Coinage, New Haven 1963. Siehe auch die Bibliographie von KOEPPEL (wie Anm. 71), 477-506, und den Forschungsüberblick: DERS,, Pictorial Tradition, ebd. 508-511. Zum Einfluß exildeutscher Archäologen auf diese internationalen Forscher siehe N. B. KAMPEN, On writing histories of Roman art, ABull 85, 2003, 371-386; zur weitgehenden Abstinenz der britischen Forschung auf dem Gebiet siehe A. WALLACE-HADRIL, Rome's cultural revolution, JRS 79, 1989, 157-164, hier 157.

${ }^{73}$ T. HÖLSCHER, Victoria Romana. Archäologische Untersuchungen zur Geschichte und Wesensart der römischen Siegesgöttin von den Anfängen bis zum Ende des 3. Jhs, n. Chr., Mainz 1967, das Zitat 2-3. 
Herrschaftsideen wie virtus, concordia und victoria am Quadrifrons oder pietas Augusti erga deos und erga homines, providentia Senatus, adventus Augusti, deductio coloniarum, annona Augusti, providentia deorum und felicitas terrarum usw. am Trajansbogen darstellen, da sie keinerlei ausdrückliche Hinweise auf bestimmte datierbare Ereignisse enthielten. ${ }^{74}$ Dieser extremen Lesart, die jeden Bezug auf das historische Einzelereignis negiert, ist man in der Regel nicht gefolgt, doch steht die Tatsache, daß die Staatsreliefs politische Leitvorstellungen repräsentieren, nicht mehr in Zweifel. Neben einzelnen Monumenten wurden auch ganze Gebäudekomplexe und ihre bildliche Ausgestaltung nach den durch sie vermittelten politischen Botschaften befragt. Im Bildprogramm des Augustusforums entschlüsselte wiederum zuerst Paul Zanker, später dann ausführlich Martin Spannagel, eine Strategie der Herrschaftslegitimierung, welche letztlich auf altrömische Werte gegründet war, noble Abkunft, pietas gegenüber Göttern und Vorfahren, virtus und dignitas, wie sie die principes viri repräsentierten, aber auch gerechte Rache und Sieghaftigkeit. ${ }^{75} 1980$ erschienen Tonio Hölschers nach wie vor wegweisende grundsätzlichere methodische Überlegungen zur „Geschichtsauffassung in der römischen Repräsentationskunst“ ${ }^{76}$ Darin heißt es etwa mit Bezug auf die Becher von Boscoreale:

„Die realen historischen Vorgänge sind hier also nach zwei abstrakt-gedanklichen Konzepten gefiltert: zum einen nach dem verfassungspolitischen Gesichtspunkt des Verhältnisses zwischen dem Kaiser als oberstem Kriegsherrn und seinem ausführenden Feldherrn; zum anderen vor allem in Hinblick auf die Exemplifizierung bestimmter ideeller Leitbegriffe, also auf ein Wertesystem, das mit dem Konzept einer Ereignisgeschichte nur in

${ }^{74}$ V. M. STROCKA, Beobachtungen an den Attikareliefs des severischen Quadrifrons von Lepcis Magna, Antiquites africaines 6, 1972, 147-172; K. FITTSCHEN, Das Bildprogramm des Trajansbogens zu Benevent, AA 1972, 742-788. Diese Art der Deutung römischer Staatsreliefs hat bis heute ihre Gültigkeit behalten, auch wenn man z. T. darauf hinwies, daß ein entsprechend disponierter Betrachter durchaus an konkrete Ereignisse wie die Einweihung der Via Trajana hatte denken können, ohne damit die Allgemeingültigkeit der Botschaft in Frage zu stellen: Hier diente das Einzelereignis - wie in der Literatur unzählige Male belegt - als exemplum für das betreffende vorbildliche Verhalten,

${ }^{75}$ P.ZANKER, Forum Augustum. Das Bildprogramm, Tübingen 1968; M. SPANNAGEL, Exemplaria principis: Untersuchungen zu Entstehung und Ausstattung des Augustusforums, Heidelberg 1999; siehe auch P. ZANKER, Das Trajansforum in Rom, AA $1970,499-544$.

${ }^{76}$ T. HöLSCHER, Die Geschichtsauffassung in der römischen Repräsentationskunst, JDAI 95, 1980, 265-321. 
sehr lockerem Zusammenhang steht, ihm in vieler Hinsicht geradezu widerspricht. "77

Und mit Bezug auf die ,Leitvorstellungen', ,Leitbegriffe“ und ,staatstragenden Ideen" stellt er allgemein fest: „Sie bilden von Anbeginn das Wertesystem, nach dem in den öffentlichen Denkmälern Roms politische Leistungen begriffen und als historische Taten der Nachwelt tradiert wurden. ${ }^{\text {"78 }}$ Daß hier jedoch die normativen Aspekte der historischen und latinistischen Werteforschung keine Rolle spielen, wird nicht zuletzt durch die Einführung des Propagandabegriffs deutlich, der unter dem Eindruck der politischen Erfahrungen des 20 . Jhs. aus der angelsächsischen Literatur zunächst in die Numismatik und dann in die deutsche archäologische Forschung eingeführt wurde. ${ }^{79}$

Noch relativ jung ist die Anwendung des historisch-soziologischen Paradigmas auf die Sarkophagkunst und damit auf eine weitere zumindest zahlenmäßig absolut zentrale Gattung der römischen Kunst. Für die Deutung der sog. Vita-humana-Sarkophage hatte, wie gesehen, bereits Rodenwaldt die Grundlage geschaffen, ${ }^{80}$ und die zentrale Botschaft der Schlachtsarkophage, victoria und virtus, war kaum zu übersehen. Die überwiegende Mehrzahl der Sarkophage ist jedoch lange Zeit allein unter kunsthistorischen Gesichtspunkten sowie als Zeugnisse teils verlorener griechischer Dichtungen behandelt worden. Die wenigen inhaltlichen Deutungen wurden vor allem von Religionshistorikern vorgelegt, welche die Sarkophage auf ihre sepulkralsymbolischen Inhalte befragten und auf religiöse Vorstellungen und Jenseitshoffnungen bezogen, ${ }^{81}$ ein Ansatz, der, trotz der grundsätzlichen Kritik von Arthur Darby Nock, bis heute nicht völlig überholt ist. ${ }^{82}$ Auch hatte Klaus Fittschen schon 1969 eine alternative

${ }^{n}$ Ebd. 287 f.

${ }^{78}$ Ebd. 271.

${ }^{79}$ H.-W. RITTER, Zur Beurteilung der Caesarischen und Augusteischen Münzpropaganda, in: K. CHRIST, E. GABBA (Hgg.), Römische Geschichte und Zeitgeschichte in der deutschen und italienischen Altertumswissenschaft während des 19. und 20. Jahrhunderts, I: Caesar und Augustus, Como 1989, 165-82; BergMANN (wie Anm. 20), bes. $218 \mathrm{f}$.

${ }^{80}$ Siehe oben Anm. 22.

${ }^{81}$ Bes. F. CUMONT, Recherces sur le symbolisme funéraire des Romains, Paris 1942; zur Forschungsgeschichte siehe G. KOCH, H. SICHTERMANN, Römische Sarkophage. Handbuch der Archäologie, München 1982, bes. 6-20; P. ZANKER, B. C. EWALD, Mit Mythen leben. Die Bilderwelt der römischen Sarkophage, München 2004, 9-27.

${ }^{82}$ Dazu ZaNKER, EWALD (wie Anm. 81), 27 mit Anm. 34; A. D. NocK, Rev. of CUMONT, Recherches sur le symbolisme funéraire des Romains, AJA 50, 1946, 150-170. Siehe etwa noch B.ANDREAE, Die Symbolik der Löwenjagd, Opladen 1985. 
Deutungslinie aufgezeigt und nachgewiesen, daß auch mythologische Sarkophage dazu dienen können, die Tugenden der Verstorbenen zum Ausdruck zu bringen ${ }^{83}$ Doch erst in jüngster Zeit hat man begonnen, diesen Deutungsansatz auch auf die gängigeren mythologischen Themen auszudehnen, ${ }^{84}$ Im Meleager- wie im Adonismythos beispielsweise sieht man nun die Darstellung von virtus und eines heroischen Todes, während man im berühmten Alkestissarkophag nicht mehr - oder jedenfalls nicht mehr nur die Hoffnung auf Überwindung des Todes ausgedrückt sieht, sondern einerseits wiederum die virtus des Junius Euhodus/Admet, andererseits die selbst den Tod nicht scheuende Hingabe der Metilia Akte/Alkestis.

Seinen noch immer anhaltenden Erfolg verdankt das historischsoziologische Werteparadigma jedoch der seit Beginn der 90er Jahre des vergangenen Jahrhunderts sich verbreitenden Einsicht, daß die Werte des mos maiorum inhaltlich offenbar $\mathrm{z}$. T. variabler ausgedrückt werden konnten, als man dies zunächst für möglich hielt, und daß sie zudem der Erweiterung bedürfen. So öffnete sich erst jetzt der Blick für die Tatsache, daß das Liebespaar eines der vorherrschenden Themen der Sarkophage ist. Irritierend und einer solchen Kategorisierung konträr schien zunächst, daß die mythischen Paare in aller Regel keineswegs die dem mos maiorum so hervorragend entsprechende Hingabe einer Alkestis zeigten, sondern äußerst problematische Beziehungen: Hades und Persephone, Luna und Endymion, Venus und Adonis, ja sogar Achill und Penthesilea sowie Hippolytos und Phädra. Der Schlüssel zum Verständnis lag schließlich in der Beobachtung, daß Mythenrezeption z. T. außerordentlich selektiv geschah und es erlaubte, ebendiese problematischen Aspekte auszublenden ${ }^{85}$ Wenn sich ein Ehepaar als Achill und Penthesilea oder als Hippolytos und Phädra darstellen ließ, so konnte wohl kaum gemeint sein, daß der Ehemann seine Frau getötet hatte - oder umgekehrt. Offenbar ging es allein um die tiefe

M. KooRTboJIAN (Myth, Meaning and Memory on Roman Sarcophagi, Berkeley u. a. 1995) versucht einen Mittelweg zu gehen und sieht die Mythen und ihre Protagonisten sowohl als exampla virtutis als auch als Ausdruck bestimmter Jenseitshoffnungen.

${ }^{83}$ K. FITTSCHEN, Ein Feldherrensarkophag im Thermenmuseum, MDAI(R) 76, 1969, 329-334; Siehe auch DERS., Zum Kleobis- und Biton-Relief in Venedig, JDAI 85, 1970, 171-193.

${ }^{84}$ ZANKER, EWALD (wie Anm. 81), bes. 179-245. Es soll allerdings nicht unerwähnt bleiben, daß die rigorosen Deutungen im Sinne reiner Tugendkataloge mittlerweile in die Kritik geraten sind, siehe ebd. und den Beitrag von S. MUTH, Im Angesicht des Todes. Zum Wertediskurs in der römischen Grabkultur (in diesem Band), 259-287.

${ }^{85} \mathrm{Vgl}$. bes. die methodologisch einschlägige Arbeit von S. MUTH, Erleben von Raum - Leben im Raum. Zur Funktion mythologischer Mosaikbilder in der römisch-kaiserzeitlichen Wohnarchitektur, Heidelberg 1998. 
und leidenschaftliche Liebe zwischen den Partnern oder die Bewunderung für einen schönen Jüngling voller virtus, die jedoch - und dies scheint die Wahl der Themen mitbestimmt zu haben - aus der Perspektive des Todes betrachtet wurden. Die Frage nach den Umständen des Todes oder gar der Schuld an diesen Toden spielte dabei keine Rolle. Die scheinbare Spannung zwischen den althergebrachten Tugenden der rechtschaffenen römischen Matrone, welche in den Grabgedichten in großer Kontinuität hervorgehoben werden, und den Liebesheroinen der griechischen Mythen löste man nun auf, indem man die Mythen als überhöhte, übersteigerte, auch emotional übersteigerte Variationen der ehelichen Zuneigung verstand, deren Details nicht eins zu eins auf den Charakter der Verstorbenen zu übertragen sind, sondern am ehesten einer Art Traumgebilde entsprechen, welches besondere Freiheiten erlaubt. ${ }^{86}$

Zugleich entstand eine neue Aufmerksamkeit für Werte jenseits von mos maiorum und clupeus virtutis. ${ }^{87}$ In Arbeiten über Gebäudeausstattungen scheute man sich nun nicht mehr, selbst die hedonistischen Aspekte der römischen Kultur zum Gegenstand der Forschung zu erheben. Dies gilt bereits für Arbeiten zur Ausstattung römischer Theater oder Thermen und hat Richard Neudeckers Pracht der Latrine erst möglich gemacht. ${ }^{88}$ Vor allem kommt dies jedoch in jüngeren Arbeiten zur Wohnkultur zum Tragen. Während ältere Untersuchungen sich noch bevorzugt den spätantiken Bilderwelten zuwandten, an denen sich das (vermeintlich) austere Weltbild

\footnotetext{
${ }^{86}$ ZANKER, EWALD (wie Anm. 81), bes. 197-217 sowie 279-381 zu einzelnen Mythen; P. ZANKER, Die mythologischen Sarkophagreliefs als Ausdruck eines neuen Gefühlskultes. Reden im Superlativ, in: K.-J. HöLKESKAMP u. a. (Hgg.), Sinn (in) der Antike. Orientierungssysteme, Leitbilder und Wertkonzepte im Altertum, Mainz 2003, 335-355; DERS., Die mythologischen Sarkophagreliefs und ihre Betrachter, SBAW, München 2000, Heft 2, 1-47; DERS., Die Gegenwelt der Barbaren und die Überhöhung der häuslichen Lebenswelt, in: T. HöLsCHER (Hg.), Gegenwelten zu den Kulturen Griechenlands und Roms in der Antike, München/Leipzig 2000, 409-433; MUTH (wie Anm. 84).

${ }^{87}$ Die Bedeutung der Tugenden des clupeus virtutis für die Staatsreliefs betont z. B. SCOTT RYBERG, Panel Reliefs (wie Anm. 72), $91 \mathrm{f}$; für die Sarkophage RODENWALDT (wie Anm. 22) und H. WREDE, Senatorische Sarkophage Roms, Mainz 2001, 33, der sie mit denen des mos maiorum gleichsetzt; dagegen jedoch die berechtigten Einwände von C. J. Classen, Virtutes Romanorum. Römische Tradition und griechischer Einfluß, Gymnasium 95, 1988, 289-302.

${ }^{88}$ M. FUCHS, Untersuchungen zur Ausstattung römischer Theater in Italien und den Westprovinzen des Imperium Romanum, Mainz 1987; H. MANDERSCHEID, Die Skulpturenausstattung der kaiserzeitlichen Thermenanlagen, Berlin 1981; R. NEUDECKER, Die Pracht der Latrine: Zum Wandel öffentlicher Bedürfnisanstalten in der kaiserzeitlichen Stadt, München 1994.
} 
des Domänenbesitzers ablesen ließ, betonte bereits die Dissertation von Richard Neudecker zur Skulpturenausstattung römischer Villen ${ }^{89}$ die Wertschätzung griechischer Bildung und arkadischer, aphrodisischer oder dionysischer Erlebniswelten im dem negotium entzogenen Bereich des Villenlebens. ${ }^{90}$ In Untersuchungen zur Ausstattung von Wohnhäusern mit Wandmalereien und Mosaiken scheint man die Versuche, anspruchsvolle und kohärente Dekorationsprogramme aufzuzeigen, weitgehend aufgegeben zu haben. Statt dessen werden die Ubiquität und sogar die Banalität der immer gleichen Szenen um Aphrodite und ihre Liebhaber, von verschiedensten glücklichen, aber auch unglücklichen Liebespaaren und von dionysischen Themen herausgestrichen. Sie holen in die Häuser Aspekte des otium, von Lebensgenuß, Luxus und griechischer Kultur, eröffnen vielfältige Anreize für die Phantasie der Betrachter. Moralisierenden Interpretationen, die etwa in der Gegenüberstellung eines Pasiphae-Bildes und der Auffindung der Ariadne im Haus der Vettier den Gegensatz zwischen der Frevlerin und der vom Gott erwählten Glücklichen erkennen möchten, werden nun Interpretationen gegenüber gestellt, welche ganz allgemein die Macht von Liebe und Erotik thematisiert finden, die zu einem fatalen wie auch zu einem glücklichen Ende führen kann. Die oft weitgehend statischen und beinahe austauschbaren Bilder von Liebespaaren wie Perseus und Andromeda, Ares und Aphrodite usw. inszenieren ebenso wie handlungsreichere Darstellungen in der Art der Entdeckung Achills unter den Töchtern des Lykomedes oder der Ergreifung des Hylas durch die Nymphen Schönheit, Begehren und Erotik, die bis zu einem gewissen Grade eine Identifikation des Betrachters mit den Protagonisten erlauben und ihn in der Phantasie in diese Traumwelten hineinziehen. ${ }^{91}$ Zwar hat man gelegentlich den Eindruck, als träfen hier eine gewisse lustvoll-erleichterte Resignation angesichts vergeblicher Versuche, die gesamte römische Welt in staatstragende "Tugendprogramme zu pressen, mit einem verhaltenen Triumph über die allzu vorbildliche Antike (und ihre Ausbeutung in der modernen Gesellschaft) zusammen. Doch wenn in der Regel auch nicht

${ }^{89}$ R. NEUDECKER, Die Skulpturenausstattung römischer Villen in Italien, Mainz 1988.

${ }^{90}$ Siehe jetzt auch MUTH (wie Anm. 85) mit neuer Deutung der spätantiken Bilderwelt.

${ }^{91}$ P. ZANKER, Mythenbilder im Haus, in: Proceedings of the XVth International Congress of Classical Archaeology, Amsterdam, July 12-17, 1998, Amsterdam 1999, 4647; MUTH (wie Anm. 85); DIES., Gegenwelt als Glückswelt - Glückswelt als Gegenwelt? Die Welt der Nereiden, Tritonen und Seemonster in der römischen Kunst, in: HöLSCHER (wie Anm. 86), 467-498. 
verneint wird, daß die mythischen erotischen oder dionysischen Traumwelten, welche die Dekoration der Häuser beherrschen, auch eskapistische Bedürfnisse befriedigt haben können, so wird doch zugleich betont, daß die Annehmlichkeiten und Genüsse durchaus in das ,klassische "Wertesystem eingebettet waren und einen akzeptierten Wert an sich darstellten. ${ }^{92}$

Auf diese Weise wird also nicht etwa das Projekt einer Suche nach römischen Werten aufgegeben, wie man zunächst meinen könnte, sondern das Spektrum römischer Werte wird vielmehr erweitert - in einen Bereich jenseits des mos maiorum und des begrenzten Tugendkanons der Inschriften. Dies hat m.E. durchaus seine Berechtigung, zumal die Untersuchungsgegenstände der Klassischen Archäologie Aspekte des antiken Lebens beleuchten können, welche aus unterschiedlichen Gründen in den schriftlichen Quellen $u$. U. nicht oder nur sehr unzureichend behandelt werden. ${ }^{93}$ $\mathrm{Zu}$ wenig beachtet scheint mir jedoch ein anderer Aspekt. Ohne daß dies in der Archäologie bisher ausreichend theoretisch reflektiert worden wäre, ist man, getäuscht durch die Konstanz der Begriffe, vielfach verleitet worden, auch eine Konstanz ihrer Inhalte zu vermuten, wobei diese Inhalte in der Regel stillschweigend auf die Vorstellungen der späten Republik und der augusteischen Zeit festgelegt wurden. Tatsächlich ist aber wohl das einzig Konstante - neben der äußerlichen Konstanz des Terminus, welche selbstverständlich ihrerseits bestimmte soziale Funktionen erfüllte - die ständige Veränderung und Neuverhandlung ihrer Inhalte. ${ }^{94}$ Insofern sollte man überlegen, ob nicht manches, was als Erweiterung des Spektrums römischer ,Werte angesehen wird, vielmehr eine neue inhaltliche Füllung altbekannter ,Wertbegriffe $e^{6}$ ist. Die gelegentlich festgestellte Diskrepanz zwischen dem unveränderten Gebrauch traditioneller ,Wertbegriffe ${ }^{6}$ in den Texten und den Leitvorstellungen und persönlichen Zielen, wie sie sich in der materiellen Kultur niederschlagen, wird nicht selten noch heute mehr oder weniger ausdrücklich als Verfallserscheinung gewertet, scheint mir jedoch mindestens z. T. auf dieses Mißverständnis bezüglich der (fehlenden) Konstanz der durch die Begriffe vermittelten konkreten Vorstellungen zurückzugehen. Macht man sich diese Gefahr jedoch bewußt, besitzt die archäologische Forschung ein besonderes Potential. So wie sie von Münzen und aus schriftlichen Quellen die römischen Begriffe ableiten kann, welche

${ }^{92}$ Ausdrücklich von ,Werten' ist etwa die Rede in ZANKER, EWALD (wie Anm. 81), z. B. 261-263, oder MUTH (wie Anm. 84).

${ }^{93}$ Man sollte sich allerdings hüten, den mos maiorum seinerseits als eine inhaltlich unveränderliche Institution anzusehen.

${ }^{94}$ Dies wird in der Alten Geschichte denn auch seit Kosellecks Arbeiten zur Begriffsgeschichte anerkannt; vgl. REBENICH (wie Anm. 51), 42-45. 
die Inhalte der Bilder in eine zeitgenössische Terminologie einbetten, kann sie ihrerseits einen eigenen und zentralen Beitrag zum Verständnis der mit den Begriffen verbundenen, sich mit der Zeit verändernden Inhalte leisten. Ein archäologischer Kommentar zum sich wandelnden Konzept des civilis princeps oder der modestia ließe sich ebenso denken wie etwa zu (griechischer) luxuria, ${ }^{95} \mathrm{zu}$ amicitia oder zur incomparabilis coniunx.

${ }^{95}$ Zum civilis princeps siehe aus althistorischer Sicht A. WALLACE-HADRILL, Civilis Princeps: Between Citizen and King, JRS 72, 1982, 32-48; aus archäologischer Sicht B. E. BORG, C. WITSCHEL, Veränderungen im Repräsentationsverhalten der römischen Eliten während des 3. Jhs. n. Chr,, in: G. ALFÖLDY, S. PANCIERA (Hgg.), Inschriftliche Denkmäler als Medien der Selbstdarstellung in der römischen Welt, Stuttgart 2001, 47120; zu luxuria und griechischer Bildung B. E. BORG, Glamorous intellectuals: Portraits of pepaideumenoi in the second and third centuries AD, in: B. E. BORG ( $\mathrm{Hg}$.), Paideia: The World of the Second Sophistic, Berlin 2004, 157-178; DIES., Traumland Ägypten: Zur Rezeption ägyptischer Luxusmotive, Städel-Jahrbuch 19, 2003/04, 191-200, je mit etwas anderer Ausrichtung. 